\title{
CAMINHOS E DESCAMINHOS DA PRÁTICA PEDAGÓGICA EM EDUCAÇÃO FÍSICA ESCOLAR: um estudo de caso com professores de uma escola pública de Santa Maria - RS
}

\author{
Marta Nascimento Marques*
}

Hugo Norberto Krug ${ }^{* *}$

\section{Resumo}

Este estudo teve como objetivo analisar as possibilidades (caminhos) e as limitações (descaminhos) encontradas na prática pedagógica de professores de Educação Física Escolar de uma escola pública de Santa Maria (RS). Este trabalho traz sua contribuição no apoio aos processos de formação inicial e permanente dos professores de Educação Física, na medida em que retrata a realidade em que os docentes convivem em seu trabalho diário nas escolas públicas. Os caminhos metodológicos que foram adotados seguiram os pressupostos da abordagem qualitativa do tipo estudo de caso. O campo de estudo da pesquisa foi uma escola pública de Santa Maria, tendo as informações coletadas da entrevista semiestruturada, realizada com três professores de Educação Física do ensino fundamental e que tinham mais de dez anos de carreira em efetivo trabalho com a disciplina. Para analisar as informações coletadas foi utilizada a análise de conteúdo. Concluiu-se que as possibilidades e limitações encontradas pelos professores são as mais diversas e o que prevalece são muito mais aspectos negativos do que positivos. Os principais descaminhos encontrados são a falta de espaço físico e material, desvalorização da Educação Física, falta de união e companheirismo entre os professores, os baixos salários, limitações quanto à maneira do professor desenvolver suas aulas, indisciplina e violência entre os alunos e dificuldades de não disporem de tempo para refletir e trocar experiências. Os caminhos apontados pelos professores foram: satisfação em dar aula, estar em contato com os alunos trocando conhecimentos, afetividade entre ambos, serem queridos e valorizados pelos alunos.

Palavras-chave: Educação Física. Caminhos. Descaminhos. Prática pedagógica.

\section{PATHS AND DETOURS OF PEDAGOGICAL PRACTICES IN THE SCHOOL OF PHYSICAL EDUCATION (PE): a case study with public school teachers in Santa Maria - RS}

\section{Abstract}

The aim of this study was to assess the possibilities (paths) and limitations (detours) found in the pedagogical practices of Physical Education teachers in public schools in Santa Maria, RS. This work contributes to the initial and ongoing training of physical education teachers, as it portrays the reality public school teachers face in their daily teaching. The methodological approaches adopted followed the assumptions of qualitative case study approach. The research field was a public school in Santa Maria, and the information was collected through semi-structured interviews carried out with three Physical Education teachers of elementary school and who

\footnotetext{
* Mestra em Educação e Professora da Rede de Ensino do Estado do Rio Grande do Sul. E-mail: martinhanm@yahoo.com.br

** Doutor em Educação e em Ciência do Movimento e professor da Universidade Federal de Santa Maria. Email: hnkrug@bol.com.br
} 
were at their jobs longer than ten years. Content analysis was used for studying the information collected. It was concluded that teachers face several possibilities and limitations and that the negative aspects are much more common than positive ones. The main detours found were lack of physical space and equipment, depreciation of the Physical Education, lack of unity and fellowship among teachers, low wage, teachers' limitations to plan their classes, indiscipline and violence in schools and difficulties due to lack of time to reflect and share experiences. The paths mentioned by the teachers were: job satisfaction, staying in touch with students and exchanging knowledge, showing affection to each other, and being loved and valued by the students.

Keywords: Physical Education. Paths. Detours. Pedagogical practice.

\section{A prática pedagógica em Educação Física e a escola como palco do estudo}

A Educação Física nos dias atuais se faz presente como uma disciplina de grande importância no currículo escolar e também de vasta abrangência, necessitando assim ser analisada com outros olhos pelos docentes e pela sociedade em geral, pois por seu intermédio é possível se desenvolver inúmeras aptidões necessárias para a formação integral do ser humano.

Embora reconhecida como uma área de conhecimento essencial, a Educação Física nas escolas, ainda não é tratada com o devido valor como as demais disciplinas, pois continua tendo suas aulas realizadas em turnos inversos das demais disciplinas, sendo a última a ser lembrada ou, às vezes, nem sendo lembrada nos momentos de planejamento, discussão e avaliação do trabalho escolar. Muitas vezes, o professor nem participa de reuniões pedagógicas da escola, por achar que seu trabalho não tem muito valor e acaba se tornando isolado ou frustrado diante de tal contexto.

A este respeito, Cristino et al. (2008) salientam a importância da participação dos professores de Educação Física nas reuniões pedagógicas e também no planejamento coletivo, com professores da mesma área, bem como de outras áreas do conhecimento, para que aconteçam processos interdisciplinares, colaborando assim para novas perspectivas educacionais. Também, de acordo com os PCN’s (BRASIL, 1997, p.24),

[...] esse professor é uma referência importante para seus alunos, pois a Educação Física propicia uma experiência de aprendizagem peculiar ao mobilizar os aspectos afetivos, sociais, éticos e de sexualidade de forma intensa e explícita, o que faz com que o professor tenha um conhecimento abrangente de seus alunos.

Para isto, segundo Darido e Neto (2005), é necessário que exista reflexão sobre o ambiente de aula por parte dos docentes e que estes se utilizem disso para seu próprio aprimoramento profissional. Sendo assim, esses momentos reflexivos poderiam servir como 
uma espécie de formação contínua, desenvolvendo essa prática no próprio ambiente da escola no desenrolar da sua prática pedagógica. Os mesmos autores afirmam ainda que "o professor deve considerar a importância de refletir em seu próprio dia a dia” (p.42). Em virtude desses momentos reflexivos o professor irá compreender que a docência é um exercício que necessita de aprendizados e melhoramentos constantes (DARIDO; NETO, 2005).

Sendo assim, é importante que haja empenho por parte do professor de Educação Física em desenvolver um bom trabalho procurando sempre em suas aulas trabalhar as múltiplas formas de expressão corporal, para que o aluno possa ter o conhecimento e a vivência das diversas manifestações corporais existentes. Além disso, vale ressaltar que os alunos precisam desenvolver ainda, durante as aulas de Educação Física, valores e atitudes positivas por intermédio de atividades que envolvam toda turma sem haver qualquer forma de exclusão.

A Educação Física exerce um papel fundamental no currículo escolar, pois, de acordo com Marques et al. (2009), a Educação Física se faz presente no contexto escolar com o objetivo de educar o aluno, auxiliando na construção de valores, no desenvolvimento de suas potencialidades motoras, cognitivas, afetivas, sociais, enfim, com a intenção de formar bons cidadãos. Mas para que aconteça essa formação de qualidade, é preciso empenho e responsabilidade por parte do professor de Educação Física, procurando em sua prática pedagógica levar em consideração uma ampla visão de mundo, isto é, visão de homem e sociedade, para poder responder a questões tais como: que tipo de aluno e sociedade quer formar? Para que sociedade este aluno vai ser formado?

Frente a tais preocupações importa mencionar o quanto se faz importante na vida profissional do docente um bom preparo inicial durante a graduação, pois esse servirá de suporte no desenrolar do contexto de ser professor, no cotidiano do ambiente escolar e no desenvolvimento de sua prática pedagógica.

No entanto, de acordo com Ghedin; Almeida e Leite (2008, p.17), os programas de ensino dos cursos de Licenciatura, de maneira geral, "estão sendo trabalhados de forma independente da prática e da realidade das escolas, caracterizando-se por uma visão burocrática, baseada no modelo da racionalidade técnica”. Frente a isso é necessário que esses programas sejam mais bem elaborados, visando à superação da racionalidade técnica e possibilitando uma base mais reflexiva para a formação e atuação do professorado, pois esses precisam ter condições básicas de compreender a importância para enfrentar os desafios que acompanham o processo de ensino-aprendizagem.

Diante destes desafios postos à formação, bem como à prática pedagógica dos 
professores de Educação Física foi que surgiu a questão norteadora desse estudo: quais são as possibilidades (caminhos) e as limitações (descaminhos) encontradas na prática pedagógica de professores de Educação Física na escola?

A partir deste questionamento, traçou-se o objetivo geral, o qual orientou a construção desse estudo. Analisar as possibilidades (caminhos) e as limitações (descaminhos) encontradas na prática pedagógica de professores de Educação Física Escolar de uma escola pública de Santa Maria (RS).

Para alcançar o objetivo geral se delineou os seguintes objetivos específicos: a) Conhecer o entendimento dos professores de Educação Física Escolar sobre a formação inicial e continuada e suas contribuições para a prática pedagógica; b) Conhecer a prática pedagógica dos professores de Educação Física Escolar, isto é, quais são os principais fatores positivos (caminhos) e negativos (descaminhos) encontrados no dia a dia do contexto educativo; e, c) Refletir sobre a prática pedagógica dos professores de Educação Física Escolar, os saberes e princípios que auxiliam na realização do seu trabalho e que contribuem na (re)significação dos (des)caminhos.

Justificou-se a realização desse estudo acreditando-se que ele poderá contribuir na formação profissional, bem como, no desenvolvimento dos professores inseridos nesse contexto, pois esse promoverá uma reflexão crítica das práticas pedagógicas vivenciadas e desenvolvidas pelos principais membros envolvidos nesse processo educativo, ou seja, os professores de Educação Física da escola palco do estudo. Ainda, acredita-se na colaboração com outros contextos formativos de formação inicial e continuada em Educação Física na medida em que se promoverá discussões e análise das práticas que vêm sendo desenvolvidas nas escolas e que merecem, sempre que possível, ser revistas e (re)significadas com a colaboração dos atores que compõem o processo.

\section{O percurso metodológico}

Este estudo caracterizou-se como sendo qualitativo, o qual tem se tornado cada vez mais comum e surge como alternativa metodológica para estudos voltados à educação. Segundo Triviños (1987) a pesquisa qualitativa não estabelece separações rígidas entre a coleta de informações e as suas interpretações, o estudo desenvolve-se como um todo, pois todas as partes estão relacionadas.

A pesquisa qualitativa desenvolve finalidades muito importantes na Educação Física Escolar, tais como: oferecer aos professores uma maneira diferente de pensar, (re)significar e 
situar sua prática em um contexto social bastante amplo; sugerir formas variadas de discutir sobre seus conhecimentos; e, dar oportunidade de os mesmos exporem seus anseios e opiniões (MOLINA NETO; BOSSLE, 2010).

A forma assumida (tipo) de pesquisa foi o estudo de caso, já que Martins (2006, p.9) afirma que "o estudo de caso possibilita a penetração em uma realidade social, não conseguida plenamente por um levantamento amostral e avaliação exclusivamente quantitativa”.

De acordo com Cauduro (2004) por intermédio do estudo de caso é possível que se realize um estudo profundo de um ou de poucos objetos, ou pessoas, de forma que se consiga um amplo e detalhado conhecimento sobre eles.

Um caso pode representar um mundo no qual muitos casos se sintam representados. Um caso constitui uma voz que pode, em um instante determinado, condensar as tensões e os desejos de outras tantas vozes silenciadas (MOLINA, 2004, p.104).

Para coletar as informações utilizou-se a entrevista já que é um dos métodos que mais facilita a interação com o campo de estudo. Usou-se a entrevista semiestruturada, pois é considerada um dos instrumentos básicos e de grande eficácia, desde que haja habilidade por parte do entrevistador. De acordo com Triviños (1987, p.146) ela:

[...] parte de certos questionamentos básicos, apoiados em teorias e hipóteses, que interessam à pesquisa, e que, em seguida, oferece amplo campo de interrogativas, fruto de novas hipóteses que vão surgindo, à medida que se recebem as respostas do informante. Desta maneira, o informante, seguindo espontaneamente a linha de seu pensamento e de suas experiências dentro do foco principal colocado pelo investigador, começa a participar na elaboração do conteúdo da pesquisa.

A utilização desta técnica também foi de grande valia porque permitiu a criação de um clima de interação recíproca entre entrevistador e entrevistado, possibilitando fluir naturalmente as informações.

Participaram do estudo três professores de Educação Física de uma escola pública de Santa Maria. Para a escolha dos participantes optou-se por professores em efetivo exercício da atividade docente no período da realização da entrevista e que tivessem mais de dez anos de carreira, por possuírem certa experiência profissional na disciplina de Educação Física. Também foi usado como critério o aceite e a disponibilidade para participar da investigação, por parte dos professores de Educação Física, pois demandou a realização de alguns encontros 
para as entrevistas e consequentemente tempo disponível pelos professores.

Os participantes da investigação, designados por nomes fictícios para preservar as suas identidades, foram os seguintes:

1) Professora Violeta: Licenciada em Educação Física pela Universidade Regional da Campanha, Campus de Bagé, concluiu sua formação inicial em 1990. Após quase dois anos de formada, realizou concurso público promovido pelo governo estadual do Rio Grande do Sul, para o cargo de professora de Educação Física. Foi aprovada, porém demorou um pouco para ser nomeada. Atualmente, desenvolve suas atividades docentes como professora de Educação Física para os Anos Finais do Ensino Fundamental e Médio, em escola da rede estadual de ensino, em Santa Maria, há 17 anos. Seu regime atual de trabalho é de 40 horas;

2) Professora Rosa: Licenciada em Educação Física pelo Centro de Educação Física e Desportos da Universidade Federal de Santa Maria e concluiu sua graduação em 1985. Possui especialização em Educação Física e mestrado em educação pela mesma universidade. Após alguns anos trabalhando em academia prestou concurso público, promovido pelo governo estadual do Rio Grande do Sul, para o cargo de professora de Educação Física. Foi aprovada e logo começou a exercer a profissão. Atualmente, desenvolve suas atividades docentes como professora de Educação Física para os Anos Finais do Ensino Fundamental e Médio, em escola da rede estadual de ensino, em Santa Maria, há 17 anos. Seu regime atual de trabalho é de 40 horas; e,

3) Professor Lírio: Licenciado em Educação Física pelo Centro de Educação Física e Desportos da Universidade Federal de Santa Maria e concluiu sua graduação em 1989. Possui especialização em Educação Física pela mesma universidade. Logo que se formou não atuou diretamente em escolas, mas como preparador físico. Já no ano de 1998 ingressou no magistério público estadual como professor contratado. Após isso, prestou concurso público, promovido pelo governo estadual do Rio Grande do Sul, para o cargo de professor de Educação Física. Atualmente, desenvolve suas atividades docentes como professor de Educação Física para os Anos Finais do Ensino Fundamental, em escola da rede estadual de ensino, em Santa Maria, há 12 anos. Seu regime atual de trabalho é de 40 horas.

Já o campo de estudo teve como palco uma escola da rede estadual de ensino do Rio Grande do Sul, localizada na zona periférica (bairro COHAB Santa Marta) da cidade de Santa Maria. A escola foi fundada em 1980 e possui desde a Educação Infantil até o Ensino Médio. Funciona em três turnos, sendo pela manhã Anos Iniciais do Ensino Fundamental, à tarde e à noite os Anos Finais do Ensino Fundamental e Ensino Médio. Possui aproximadamente 2000 alunos, 40 funcionários e 110 professores, destes, seis são professores 
de Educação Física. Os alunos integrantes da escola são de classe baixa, a maioria não possui uma boa estrutura familiar e convive com sérios problemas sociais como drogas, violência, etc. A escola não apresenta uma boa estrutura física para a realização das aulas de Educação Física, pois possui apenas uma quadra descoberta, uma área de grama e o pátio da escola. Os materiais também são poucos, como rede, bolas de vôlei, de futsal e handebol. Os horários das aulas de Educação Física acontecem no contraturno, isto é, no turno inverso das outras disciplinas curriculares, e as turmas de alunos para a Educação Física são mistas. A maioria dos alunos é assíduo e participa das aulas de Educação Física com bastante entusiasmo, demonstrando gosto pela disciplina, com exceção dos alunos do noturno que muitos deles trabalham, são amparados pela lei (dispensa) e os que praticam são bastante infrequentes. Na questão do planejamento os professores de Educação Física procuram se guiar pelo Projeto Político-Pedagógico da escola, cada um planejando suas próprias aulas. Realizam reuniões semanais para assuntos gerais, mas nem sempre há a participação de todos. Não existem muitos momentos de planejamento e trocas entre os professores de Educação Física, pois cada um está mais preocupado em cumprir seu horário e ministrar suas aulas. Normalmente não se encontram porque trabalham em turnos diferentes.

Para este estudo foi significativo o uso da análise de conteúdo para a interpretação das informações, pois essa, segundo Martins (2006, p.35), “é uma técnica de grande eficácia, porque busca a essência da substância de um contexto nos detalhes dos dados e informações disponíveis”.

Bardin (1977) coloca que a análise de conteúdo representa um conjunto de técnicas para analisar comunicações, que buscam desvelar por intermédio de procedimentos sistemáticos e objetivos de descrição do conteúdo das mensagens, indicativos que possuem a inferência de conhecimentos relativos às condições reais das mensagens. Salienta ainda que a análise de conteúdo apresenta três fases, sendo elas: 1) A pré-análise - que se refere à organização do material; 2) A descrição analítica - onde o material coletado é submetido a uma análise sistemática e aprofundada, embasada no referencial teórico do estudo. Os procedimentos realizados nessa fase são a codificação, a classificação e a categorização; e, 3) A interpretação referencial - são as análises realizadas até esta fase são submetidas a uma reflexão mais intensa, buscando desvelar elementos ocultos.

No que tange aos aspectos éticos desta pesquisa, destacou-se que ela foi aprovada pelo Comitê de Ética em Pesquisa com Seres Humanos da UFSM (CAAE No 0232.0.243.000/10). 


\section{A prática pedagógica dos professores de educação física: caminhos e descaminhos que fazem parte do contexto escolar}

\section{As concepções de formação inicial e continuada em Educação Física: contribuições para à prática pedagógica na escola}

O ser professor envolve uma série de fatores, entre eles a formação inicial e a continuada, as quais farão parte de toda a carreira docente, que, de acordo com García (1999), é um processo contínuo, sistemático e organizado que se inicia com a formação inicial e segue com a formação continuada, sendo necessária a implementação das atividades formativas durante todos os níveis da carreira. Também é fundamental que exista uma relação entre a formação inicial e a continuada, para que haja uma maior coerência e qualidade no processo formativo dos professores, auxiliando assim na melhoria da prática pedagógica.

Neste sentido, a formação do professor não pode ser encarada como uma tarefa isolada da escola, mas sim deve abranger esse contexto, construindo habilidades e conhecimentos que permitam ao professor estruturar suas ações e as relações estabelecidas com os alunos no contexto escolar.

Assim, neste contexto de formação, em especial do profissional de Educação Física, Molina Neto e Molina (2003) apontam para a importância de que a formação ocorra num processo contínuo e em permanente revisão, levando sempre em conta os saberes que os profissionais já adquiriram antes da formação e também no seu contexto de trabalho. Sendo assim, os saberes, conhecimentos e fazeres da Educação Física precisam ser problematizados à luz dos debates dos processos formativos, para que cada vez mais auxiliem na prática diária do professor, bem como no desenvolvimento dos alunos.

Sobre as concepções de formação inicial e continuada se percebeu por intermédio das falas dos professores participantes (Violeta, Rosa e Lírio), que seus entendimentos sobre formação são um pouco difusos, mas os três salientam sobre a importância destas nas suas práticas educativas e desenvolvimento como profissionais de Educação Física. Quando se referem à formação inicial, ficou evidente que os professores esperavam mais do curso de graduação, ter um preparo maior, uma bagagem mais ampla de conhecimentos, pois essa é a base imprescindível para a atuação docente na escola. Os professores também conseguem identificar que ações de formação continuada podem acontecer na própria escola, com os colegas, [com base em] reflexões e trocas.

Os três professores colocam que entendem que estamos sempre em formação, que esta é contínua em todos os momentos da nossa trajetória formativa. Existe também uma 
unanimidade entre eles, de que a formação continuada possibilita uma atualização, manter-se informado do que está acontecendo, para "não parar no tempo”. Porém na fala de uma das professoras (Violeta), observou-se certa deficiência quanto à oferta de formação continuada no contexto escolar voltado para a área da Educação Física em relação às outras disciplinas, necessitando assim ter que buscar essa formação fora da escola.

Na fala de uma das professoras (Violeta) se percebeu um pouco de preocupação sobre o efetivo funcionamento das políticas públicas porque pelo visto para muitas escolas, sucesso escolar é somente sinônimo de aulas dadas e a função primordial do professor é o exercício da docência, o trabalho com os alunos. Talvez o que ajudaria nesse embate é que fossem colocados em prática mais espaços de estudos e formação e também o professor pudesse sair um pouco da sala de aula para aprimorar sua aprendizagem da docência em outros espaços da escola, abrindo seus olhos e se posicionando com firmeza sobre seus direitos de qualificação profissional que influenciam também na qualidade da educação.

Neste viés, notou-se que esses professores de Educação Física (Violeta, Rosa e Lírio) necessitam de formações continuadas que venham a responder anseios da sua prática pedagógica, principalmente quando os conhecimentos da formação inicial não mais dão conta de responder, pois por intermédio desses encontros terão a possibilidade de discutir e problematizar suas práticas pedagógicas e questões que envolvem seu contexto de atuação.

Ainda no entendimento dos professores (Violeta, Rosa e Lírio) a formação inicial e a continuada não se separam, pois a primeira acontece na graduação e, enquanto acadêmico, deve-se sempre buscar a participação em cursos, fazer pesquisas, para ter uma boa base para a futura vida profissional e consequentemente como professor essa busca deve intensificar-se ainda mais para estar sempre atualizado e não se tornar acomodado, porque as coisas estão sempre em mudança e o professor precisa acompanhá-las para ter condições de desenvolver uma educação de qualidade com seus alunos.

De acordo com Nóvoa (1995) o aprender contínuo é fundamental na profissão professor. Ele deve se concentrar em dois pilares: a escola, como lugar de crescimento profissional permanente e a própria pessoa do professor, como agente deste. Destaca também que mais importante do que formar é formar-se; que todo o conhecimento é autoconhecimento e que toda a formação é autoformação. Por isso, a prática pedagógica inclui o indivíduo, com suas singularidades e afetos. 


\section{Um olhar crítico sobre a prática pedagógica na Educação Física Escolar dos professores}

A prática da Educação Física, em seu caráter pedagógico, envolve uma forte relação de docência, na qual devem sempre estar presentes a interação, o ensino e a aprendizagem. Portanto, é necessário que existam momentos de reflexão sobre a prática pedagógica, no sentido de provocar mudanças de atitudes e melhoria no aprendizado dos indivíduos que nela estão envolvidos.

De acordo com estudo realizado por Günther e Molina Neto (2000) as diferentes práticas pedagógicas dos professores de Educação Física se compõem pela conjugação entre as influências adquiridas ao longo de um processo de socialização com os colegas durante o exercício docente, por intermédio de conhecimentos adquiridos no fazer pedagógico do dia a dia, bem como com os valores e crenças pessoais que fazem parte do contexto profissional.

Entre os professores entrevistados (Violeta, Rosa e Lírio), observou-se que há uma tendência de querer melhorar a qualidade de suas práticas pedagógicas, considerando que [essas] não estão sendo voltadas para o desenvolvimento integral do seu aluno, acham que é preciso um maior envolvimento do professor, sempre tentando rever, com base em diferentes concepções, as possibilidades da Educação Física Escolar.

Também se observou a consciência dos professores pela busca de um caminho transformador e pela tentativa de mudanças frente à realidade da educação e das suas práticas como professor de Educação Física, pois essa mudança depende muito do seu engajamento como docente, de querer fazer melhor, dar importância para o desenvolvimento do seu aluno, dispor de seu tempo e estar constantemente empenhado em formar cidadãos autônomos e preparados para enfrentar a sociedade atual.

Conforme Krug (2001), ao mesmo tempo em que há o desejo de melhorar a prática pedagógica, também é evidente que essa mesma prática continua ultrapassada, emaranhada por uma imobilidade que não permite avançar na construção de uma prática educativa onde o professor se reconheça como um profissional reflexivo, crítico e que busca transformar a perspectiva educacional.

Assim como existe a dificuldade em sistematizar o trabalho coletivo e reflexivo nas escolas em que ela acontece, mas poderia expandir-se mais, também ocorre certa dificuldade dos professores de Educação Física em compreenderem e aceitarem algumas especificidades da área, impedindo, muitas vezes, atuações mais intensivas na organização escolar (CRISTINO, 2007). 
Assim, em contraposição às falas dos professores entrevistados (Violeta, Rosa e Lírio), isto é, de melhoria da qualidade das aulas, na busca de um caminho transformador das práticas pedagógicas, aparecem os condicionantes sociais, principalmente, o relacionado à dificuldade de se trabalhar o coletivo com base na reflexão sobre as ações realizadas.

E, neste sentido, segundo Ilha; Marques e Krug (2010), o que ocorre na Educação Física Escolar para as mudanças se desencadearem lentamente, é que, muitas vezes, os próprios professores duvidam das novas dinâmicas, considerando a forma tradicional/tecnicista o jeito mais fácil ou mais cômodo de ensinar. Outro fator citado pelos autores que desencadeia a comodidade são as péssimas condições físicas das escolas, principalmente as públicas, pois para inovar sem muito espaço e material é preciso muita criatividade por parte do professor. Também pelo local de trabalho ser muitas vezes até fora do pátio da escola, o professor de Educação Física parece estar permanentemente isolado na sua prática pedagógica. Com isso muitos professores acabam se acostumando a um trabalho solitário e sentem dificuldades em se associar aos demais, tanto quanto falta iniciativa das supervisões se aproximarem dos locais onde acontecem as aulas.

Segundo Krug (2001), muitas vezes, no contexto educativo, o que também acontece é de nos deparamos com práticas impensadas e rotineiras, reproduzidas com base nas das aparentes competências práticas do professor, com conhecimentos repetidos e tradicionais, os quais são aplicados para qualquer situação ou realidade. Os professores parecem incapazes de estabelecerem o diálogo criativo, empobrecendo cada vez mais seus pensamentos e cometendo erros que nem eles sequer conseguem detectar.

Para Pérez Gómez (2000), os professores precisam estar envolvidos e motivados para que ocorra esse processo de mudança na prática. Somente quando existir disponibilidade e participação voluntária, pode-se falar em mudança como melhora ou aperfeiçoamento educacional.

Porém, o que acontece é que assim como a participação nas atividades de formação desperta nos professores entusiasmo e desejo de transformar na intervenção pedagógica, muitas vezes, esse estado de ânimo é vencido pela rotina docente e pela falta de perspectiva, faltando meios de intensificar esta motivação no cotidiano da escola (GÜNTHER; MOLINA NETO, 2000). 


\section{Os desafios do cotidiano educacional: os descaminhos que se apresentam na Educação Física Escolar}

Refletir sobre os professores, em especial o professor de Educação Física, suas práticas educativas e a realidade vivida por este no cotidiano escolar é uma confrontação com um grande leque de desafios, pois não é de hoje que o sistema educacional brasileiro vem desabando, acompanhado de uma crise de referências que estamos vivendo em termos de civilização e a Educação Física está fortemente envolvida por essa crise ou mesmo desvalorizada.

No cotidiano escolar é grande a carga de queixas por parte dos professores, pois, segundo Vasconcellos (2007, p.15), “no tempo atual, um professor que não tenha um nível razoável de angústia em relação à sua atividade, que não se sinta desacomodado, com certeza, não é um professor do tempo atual”!

O que, muitas vezes, acontece é que sobre o professor é colocada a responsabilidade de educar, de formar cidadãos e quando acontece o fracasso escolar a culpa também é do professor, no entanto, os professores e alunos são vítimas de uma política educacional que não prioriza o desenvolvimento da educação. Os professores são vítimas ainda da falta de interesse da sociedade na construção de sua valorização profissional, com base em salários dignos, formação continuada adequada, de melhores condições físicas e materiais para as escolas (GHEDIN; ALMEIDA; LEITE, 2008).

Nas entrevistas, os professores de Educação Física (Violeta, Rosa e Lírio) deixaram transparecer que os diversos tipos de dificuldades que encontram no cotidiano escolar não se diferem das colocadas pela literatura especializada. Entre elas, foram relatadas a desvalorização da Educação Física, os problemas de espaço físico e material, os baixos salários, que acabam desmotivando o professor na busca de mais dedicação no enfrentamento das limitações quanto à maneira do professor desenvolver suas aulas. Também foram colocadas por dois professores (Rosa e Lírio) as dificuldades quanto ao relacionamento, indisciplina e a violência entre os alunos, frutos dos valores da sociedade atual que acaba interferindo no trabalho e desenvolvimento das aulas do professor.

Neste viés Ghedin; Almeida e Leite (2008) deixam claro que "compreender os caminhos e descaminhos da prática” é uma tentativa de interpretar o modo de ser de cada professor no dia a dia do contexto escolar. Também colocam que é com base em ações, tanto pessoal como institucional, que o professor irá projetar o seu modo de ser, na tentativa de cada vez ser mais e melhor. 
Assim, constatou-se, que o trabalho do profissional de Educação Física é dificultado, na maioria das vezes, por diversos fatores, como falta de materiais e de espaço adequado, desvalorização da sociedade e de outros profissionais etc. Porém esses empecilhos não devem comprometer o trabalho desses profissionais e nem ser argumentos para o seu comodismo e descomprometimento com a profissão.

De acordo com Marques e Krug (2009) os principais problemas sentidos pelos professores de Educação Física no decurso de suas carreiras estão relacionados à falta de condições em termos físicos e materiais para o desenvolvimento das aulas de Educação Física, dificuldades em organizar o processo de ensino-aprendizagem, número excessivo de alunos em aula, desajustamento dos programas, atitude de passividade e/ou de não colaboração dos colegas, inexistência de medidas adequadas ao controle do insucesso escolar, alunos indisciplinados com falta de interesse e/ou concentração nas aulas e ainda a falta de acompanhamento da família, caracterizando uma desvalorização do trabalho do professor.

Conforme Darido e Neto (2005) também é bastante comum se observar a falta de privacidade existente nas aulas de Educação Física, pois o professor e os alunos quase sempre contam com expectadores em suas aulas, como pessoas da direção, funcionários da escola, alunos de outras turmas, pais etc. Todos esses elementos de alguma forma interferem no desenvolvimento das aulas, muitas vezes, atrapalhando a concentração dos próprios alunos e isso acaba dificultando a prática pedagógica do professor. Já nas outras disciplinas isso não acontece, pois se pode manter a porta da sala fechada e ter mais privacidade para desenvolver o trabalho.

Essa cultura escolar, para muitos dos professores de Educação Física, tornou-se cômoda e segura. Para outros ainda não, sendo [freqüente] o professor sentir-se impotente diante dela e incomodado com essa rotina. Alguns analisam tais situações como obstáculos para que desenvolvam suas propostas pedagógicas (DARIDO; NETO, 2005, p.113).

Apesar de todas as dificuldades e empecilhos que o professor de Educação Física enfrenta no seu cotidiano, ele ainda se sente desvalorizado, deixado de lado pela comunidade escolar, parece que esse professor possui utilidade e competência apenas para dar aulas.

Segundo Pérez Gómez (2001) são inúmeros os fatores que afligem a competência profissional do professor, emaranhando-o numa sensação cada vez maior de insegurança, estresse e impotência frente aos problemas que encontra, tornando-se cada vez mais dependente e carente de iniciativas, à espera de determinações e recomendações da coordenação ou direção da escola. 
É reconhecido ainda que os professores são mal remunerados e, portanto, trabalham mais do que suportam para manter um padrão de vida um pouco mais digno. Para isso eles precisam trabalhar em várias escolas, precisando se deslocar de uma para outra, e tudo isso em um tempo mínimo, o que na maioria das vezes impede que o professor tenha um maior envolvimento e dedicação com a comunidade escolar. Além disso, acaba sendo quase impossível a troca de experiências com os colegas a qual é tão importante para o desenvolvimento de seu trabalho (DARIDO; NETO, 2005).

Diante deste cenário de dificuldades, condições de trabalho inadequadas, falta de espaço físico, materiais insuficientes para desenvolver as práticas, falta de tempo para refletir, dialogar e exercer a troca de saberes entre os professores, evidenciou-se a forte necessidade de se produzirem mudanças na prática dos professores e na própria escola, para que, de maneira mais eficaz, consiga se buscar novos caminhos para o desenvolvimento profissional e também dos educandos.

\section{A reflexão e a troca de saberes como aliadas para enfrentar os descaminhos}

Partiu-se da ideia de que o professor deve considerar sempre a importância de refletir no seu próprio dia a dia, de como foi a sua aula, quais os pontos positivos (caminhos) e negativos (descaminhos), o que fazer para superar as dificuldades, enfim, que estratégias utilizar para tal. Assim, acreditamos que a reflexão e a troca de saberes entre os colegas sejam alguns dos meios eficazes que irão auxiliar nesse sentido.

Conforme Krug (2006) os professores devem ser incentivados a refletirem sobre suas práticas, para perceberem a importância de exercer um diálogo reflexivo entre os colegas, pois por intermédio disso estarão revisando seu trabalho docente e também apontando aspectos que podem ser melhorados em suas aulas e no contexto escolar.

Apesar da grande importância que a troca de saberes e a reflexão sobre a prática exercem nas escolas, constou-se nas entrevistas que, infelizmente elas ainda precisam ser mais bem desenvolvidas entre os professores.

Percebeu-se por intermédio da fala dos professores de Educação Física (Violeta, Rosa e Lírio) que os momentos de refletir e trocar saberes no ambiente escolar ainda são muito raros, porém, eles possuem consciência que o grande foco está realmente no exercício da troca, do diálogo e da reflexão entre professores e também alunos, pois o bom desempenho profissional depende da capacidade crítica-reflexiva. Bons professores são aqueles que demonstram insatisfação com as práticas, mas que promovem mudanças e lutam juntos para 
superá-las, pois a reflexão e ação numa vivência de grupo têm maiores possibilidades de conseguir melhorias e conquistas na educação do que ações isoladas.

É perceptível no meio profissional que os professores tenham capacidade de exercerem a reflexão, porém essa tarefa, muitas vezes, acaba se tornando um pouco difícil.

Difícil pela falta de tradição. Difícil, eventualmente, pela falta de condições. Difícil pela exigência do processo de reflexão. Difícil, sobretudo, pela falta de vontade de mudar [...] o pior defeito é a comodidade de atribuir a culpa de todos os males aos outros. Ninguém deve ser obrigado a ser reflexivo, embora todos devam ser estimulados a sê-lo. E o todo começa em cada um de nós (ALARCÃO apud KRUG, 2006, p.83).

Os professores (Violeta, Rosa e Lírio) reconhecem a necessidade de haver mais trocas de saberes e reflexão sobre a prática no ambiente escolar, mas ao mesmo tempo consideram que isso depende muito do interesse de cada professor em buscar exercer tal prática, seja com colegas da Educação Física ou de outras disciplinas. Também deixam claro que tal atividade depende muito da política da escola em que o profissional está inserido.

Ainda, por intermédio da reflexão o professor pode transformar-se num investigador da sua própria prática e com isso entender melhor vários acontecimentos que ocorrem, não só em relação as suas aulas, mas sobre todo o contexto de sua escola e de sua profissão. Assim terá condições de trocar informações com colegas tanto de Educação Física como de outras disciplinas. Assim, concordou-se com a afirmativa de Nóvoa (1992) de que "a troca de experiências e a partilha de saberes consolidam espaços de formação mútua, nos quais cada professor é chamado a desempenhar, simultaneamente, o papel de formador e formando" (p.26).

No entanto, um fator bastante complexo é o tempo dos professores de escola pública, que cada vez está mais reduzido ao espaço da quadra, devido à carga horária praticamente preenchida com turmas, faltando assim o tão desejado espaço para reflexão do professor.

Portanto, é fundamental que exista um espaço para os professores nas escolas, que não seja somente dar aula, é preciso,

[...] que os professores tenham regularmente um tempo, fora da sala de aula, e em um contexto em que se sintam bem, para falarem sobre o seu trabalho, para darem voz ao cotidiano escolar. Também é importante que os professores critiquem, para que possam rever suas práticas, substituindo-as por outras melhor fundamentadas e que resultem eficientemente para os fins educacionais a que se propõem ou, mais que isso, para que possam saber se suas decisões educacionais estão de acordo com os projetos políticos e culturais de seu país, os quais se comprometeram desenvolver em suas aulas 
(NEIRA, 2006, p.21).

De acordo com Neira (2006) também é importante que o professor leve em consideração que apesar da aula ser um momento de trabalho coletivo, cada aluno tem suas particularidades e momentos diferentes de aprendizagem e construção do conhecimento. Dessa forma, devem ser bastante estimulados a serem sujeitos da construção do conhecimento, mediados pelo professor que é o agente responsável por esse processo.

Nesta perspectiva é fundamental que o professor procure aproveitar todas as possibilidades de interações que possam surgir na escola para que cada vez mais consiga ampliar a qualidade de suas aulas, transformando os descaminhos em caminhos e contribuindo de maneira positiva na melhoria da educação.

\section{Não só de pedras são os caminhos: o lado positivo da Educação Física}

Na área da Educação Física Escolar, um bom trabalho, com objetivos claros, sequência de conteúdos e fundamentação da docência está fortemente relacionado com as possibilidades de desenvolvimento profissional existentes e do exercício da reflexão que se estabelece permanentemente desde a formação inicial até a formação em serviço.

À luz de uma proposta pedagógica a disciplina de Educação Física é portadora de um vasto conhecimento capaz de levar os alunos de todas as faixas etárias a vivenciarem a sua cidadania de forma autônoma. É possível também que a Educação Física “articule criticamente uma concepção que possa ser explorada e transformada pelos alunos, pois irá permitir um ensino capaz de ampliar os argumentos sobre a importância da inserção e integração da Educação Física na cultura corporal” (DARIDO; NETO, 2005, p.61).

Considerando que a principal finalidade pedagógica da Educação Física é o corpo, dessa forma, é no professor que reside o grande compromisso de propor desafios e reflexões que auxiliem no desenvolvimento integral dos seus alunos, na autocompreensão e também na compreensão do coletivo por meio do movimento, pois se sabe que todo movimento é dotado de significado e traz consigo elementos da cultura e do contexto de onde se origina.

Certamente este é um grande desafio, pois, como coloca Santin (1999), a disciplina de Educação Física nem sempre faz parte do processo educacional propriamente dito. Portanto, uma das possibilidades de integrá-la efetivamente está na nova relação que a sociedade contemporânea estabeleceu com o corpo. Dessa forma, pela conquista de novos espaços, para além do esporte, a Educação Física pode e deve construir sua própria identidade e autonomia 
pedagógica.

Por intermédio das falas os professores (Violeta, Rosa e Lírio) ressaltam a importância do professor de Educação Física desenvolver um bom trabalho com seu aluno, deixando bem claro os objetivos e a importância de sua disciplina, para que o aluno aprenda a dar valor e ter essa disciplina como indispensável para seu desenvolvimento e para sua vida.

Outro ponto importante, colocado por uma professora (Rosa) diz respeito ao lado humano e afetivo existente nas aulas de Educação Física, onde existe a possibilidade de serem trabalhados valores e comportamentos que serão úteis para a vida toda dos alunos.

Nesta direção de ideia, Darido e Neto (2005, p.109) reforçam esse posicionamento ao colocar que "o movimento humano é uma das formas mais fundamentais de interação social e requer uma relação íntima das pessoas entre si e o universo. Essa interação proporciona uma grande intimidade que guarda os aspectos específicos de cooperação e competição”.

Também nas falas os professores (Violeta, Rosa e Lírio) enfatizam a alegria que sentem em dar aula, em estar em contato com os alunos, trocando conhecimentos com eles. Então a prática educativa deve ser feita com alegria, mesmo que nem sempre se consiga o envolvimento de todos os alunos, mas o professor deve estar sempre preocupado em criar esse clima de satisfação e participação de seus alunos.

Em concordância a isto, vale ressaltar, a importância de existir uma boa relação professor-aluno, pois:

[...] por mais bem elaboradas que possam parecer, as estratégias metodológicas utilizadas para o ensino e a aprendizagem de algum conteúdo só serão bem-sucedidas se os alunos dela participarem efetivamente, e esses só o farão se o professor propuser desafios, comparar, dirigir, estiver atento á diversidade dos alunos e diversificar essas estratégias quando necessário, ou seja, os professores devem estabelecer uma relação direta com os alunos (DARIDO; NETO, 2005, p.109).

A Educação Física está inserida no contexto escolar como atividade pedagógica e, portanto, não pode deixar de cumprir sua função de formação ética do indivíduo. Essa formação acontece nas aulas em contato com os demais, onde estão envolvidos os conflitos éticos gerados pela cultura corporal de movimento que são: conhecimento dos limites e possibilidades do próprio corpo, ter autodisciplina, saber competir e cooperar, aprender e respeitar às regras, participar na construção de novas regras, saber utilizar ou não de substâncias estranhas à prática esportiva etc. (NEIRA, 2006).

Estas são questões que fazem parte dos caminhos para um bom desenvolvimento da 
prática pedagógica dos professores de Educação Física e numa boa relação ensinoaprendizagem.

Além disto, outro ponto que se considerou como positivo na Educação Física Escolar, diz respeito ao nível de satisfação que o profissional sente ao desenvolver em suas aulas conteúdo do qual ele gosta, também o bom relacionamento que tem com alunos, pais e colegas, o prazer em trabalhar em diferentes ambientes e não somente fechado em uma sala de aula, o reconhecimento e gosto que os alunos demonstram por suas aulas, bem como o desenvolvimento de diferentes tarefas no ambiente escolar (ANDREWS apud BOTH; NASCIMENTO, 2009).

Tais aspectos contribuem num bom desenvolvimento da prática pedagógica dos professores, numa boa relação professor-aluno e em consequência disso, num bom aproveitamento e aprendizagem dos educandos.

\section{Educação fisica escolar: caminhos... Descaminhos... Por onde seguir?}

Ao finalizar este estudo percebeu-se o quão pouco se sabe e do quanto ainda precisa-se aprender e aprofundar mais os conhecimentos para os professores poderem enfrentar os diversos descaminhos que se apresentam nessa trajetória profissional, na tentativa de transformá-los em caminhos melhores para uma Educação Física de qualidade.

Para o melhor entendimento das interpretações apresentadas, cabe destacar que os caminhos mencionados podem ser traduzidos naquilo de positivo que os professores encontram em seu trabalho e que ajudam no processo de ensino-aprendizagem. Quanto aos descaminhos, esses podem ser compreendidos como as limitações, o que encontram de negativo e que prejudica o desenvolvimento de suas práticas.

Por intermédio das entrevistas feitas com os professores se identificou comentários e reflexões desses quanto às dificuldades de não disporem de tempo para refletir e trocar experiências, avaliar suas práticas mais detidamente, pela sobrecarga de atividades, inclusive em mais de uma escola, além do cansaço físico e, sobretudo, emocional das jornadas diárias de ensino.

Também foram muito marcantes os discursos dos docentes em torno das dificuldades de se apropriarem de novos saberes, uma vez que os cursos de formação continuada dos quais participaram possuem limitações em apresentar e explorar aspectos relacionados com a sua disciplina, além disso, as possibilidades de formação permanente na sua área podem tornar-se de elevado custo, horário problemático e pouco relacionados à singularidade de cada realidade 
escolar.

Sobre as concepções de formação inicial e continuada se percebeu por meio das falas dos professores participantes, que seus entendimentos sobre formação são um pouco difusos, mas os três salientam sobre sua importância nas práticas educativas e desenvolvimento como profissionais de Educação Física. Quando se referem à formação inicial, ficou evidente que os professores esperavam mais do curso de graduação, ter um preparo maior, uma bagagem mais ampla de conhecimentos, pois essa é a base imprescindível para a atuação docente na escola. Os professores também conseguem identificar que ações de formação continuada podem acontecer na própria escola, com os colegas, por intermédio de reflexões e troca de saberes.

Existe também uma unanimidade entre os professores, de que a formação continuada possibilita uma constante atualização, dessa forma, poderão manter-se sempre informados do que está acontecendo, também colocaram a importância de “não parar no tempo”, estar sempre buscando novos conhecimentos.

Nas entrevistas, os professores de Educação Física deixaram transparecer que os diversos tipos de dificuldades que encontram no cotidiano escolar não se diferem dos citados pela literatura especializada. Entre eles, foram relatados a desvalorização da Educação Física, os problemas de espaço físico e material, os baixos salários que acabam desmotivando o professor de buscar mais conhecimentos e, algumas limitações quanto à maneira do professor desenvolver suas aulas. Também foram colocadas por dois professores as dificuldades quanto ao relacionamento, indisciplina e a violência entre os alunos, frutos dos valores da sociedade atual que acabam interferindo no trabalho e desenvolvimento das aulas do professor.

Por outro lado, observou-se, por intermédio das falas dos três professores participantes desse estudo, a revelação de um sentimento de luta e de resistência que os move frente aos descaminhos que encontram em seu contexto profissional e a esperança e vontade de transformar esses descaminhos em caminhos para uma Educação Física mais valorizada e de melhor qualidade.

Os questionamentos e as preocupações sobre a prática pedagógica em Educação Física Escolar caminham por estradas permeadas por dificuldades, incertezas e insegurança, porém a continuidade na busca de transformá-las em possibilidades, certezas e segurança ainda é um desafio para estes professores. No entanto, esse caminho já possui um ponto de partida: um trabalho que possibilite a troca e a reflexão no ambiente escolar, a partir da visão de totalidade sobre os aspectos relevantes e imediatos do trabalho pedagógico.

Para isto é necessário que o professor reflita sobre o seu próprio fazer cotidiano, para poder produzir novas atitudes, para assim construir novos conhecimentos, procurando sempre 
efetuar um diálogo entre a sua didática e a sua prática, tornando-se um mediador e proporcionando em suas aulas momentos de reflexões, que favoreça espaço para respostas críticas do alunado.

Entre os professores entrevistados, percebeu-se que há uma tendência em querer melhorar a qualidade de suas práticas pedagógicas, considerando que estas não estão sendo voltadas para o desenvolvimento integral do seu aluno, acham que é preciso um maior envolvimento do professor, sempre tentando rever, por intermédio de diferentes concepções, as possibilidades da Educação Física Escolar.

$\mathrm{Na}$ fala de um dos professores entrevistados constatou-se a consciência pela busca de um caminho transformador e pela tentativa de mudanças frente à realidade da educação e das suas práticas como professor de Educação Física, pois esse afirmou que tal mudança depende muito do seu engajamento como docente, de querer fazer melhor, dar importância para o desenvolvimento do seu aluno, dispor de seu tempo e estar constantemente empenhado em formar cidadãos autônomos e preparados para enfrentar a sociedade atual.

É perceptível que a qualidade de ensino está diretamente ligada às possibilidades de formação profissional dos professores, bem como o exercício da reflexão e da troca de saberes. Na Educação Física, são visíveis as dificuldades formativas e também no desenvolvimento das práticas dos professores, se evidenciando, muitas vezes, a falta de inovações pedagógicas. Devido à amplitude dessa área, ainda falta um maior consenso sobre o caminho a seguir, quais seriam as alternativas eficazes para melhorar a prática pedagógica, superar os descaminhos e dar um novo sentido a disciplina.

Apesar de a realidade ser de dificuldades formativas, de condições de trabalho inadequadas e desvalorização profissional, felizmente ainda existem professores preocupados em (re)significar esse contexto, buscando qualidade e novos caminhos para a área de Educação Física Escolar.

Além disto, os professores enfatizam a satisfação que sentem em dar aula, em estar em contato com os alunos, trocando conhecimentos com eles, e consideram que a prática pedagógica deve ser feita com alegria, mesmo que nem sempre se consiga o envolvimento de todos os alunos, mas o professor deve estar sempre preocupado em criar esse clima de satisfação e participação de seus alunos, pois a aula de Educação Física proporciona o lado humano da comunicação entre as pessoas e isso leva a uma forte interação e afetividade.

Percebeu-se ainda nas falas dos professores de Educação Física (Violeta, Rosa e Lírio), que o grande foco está realmente no exercício da troca, do diálogo e da reflexão entre professores e também alunos, pois o bom desempenho profissional depende da capacidade 
crítico-reflexiva. Bons professores são aqueles que demonstram insatisfação com as práticas, mas que promovem mudanças e lutam juntos para superá-las, pois a reflexão e ação numa vivência de grupo têm maiores possibilidades de conseguir melhorias e conquistas na educação do que ações isoladas.

Enfim, muitos outros caminhos e descaminhos ainda serão percorridos e por isso será preciso haver comprometimento numa busca constante para ultrapassar as limitações e (re)construir o caminho nada suave da Educação Física.

\section{Referências}

BARDIN, L. Tradução de Luis Antero Neto e Augusto Pinheiro. Análise de conteúdo. Lisboa: Edições 70, 1977.

BOTH, J.; NASCIMENTO, J.V. Intervenção profissional na Educação Física Escolar: considerações sobre o trabalho docente. Revista Movimento, Porto Alegre, v.15, n.02, abr./jun., 2009 (pp.169-186).

BRASIL. PCN - Parâmetros Curriculares Nacionais: Educação Física. Secretaria de Educação Fundamental. Brasília: MEC/ SEF, 1997.

CAUDURO, M.T. Pesquisa: a construção de um conhecimento. In: CAUDURO, M.T. (Org.). Investigação em Educação Física e esportes: um novo olhar pela pesquisa qualitativa. Novo Hamburgo: Feevale, 2004 (pp.19-28).

CRISTINO, A.P. da R. Um olhar crítico-reflexivo sobre a formação continuada de professores de Educação Física da rede municipal de ensino de Santa Maria (RS), 2007. 162 f. Dissertação (Mestrado em Educação) - Universidade Federal de Santa Maria, Santa Maria, 2007.

CRISTINO, A.P. da R. et al. Reuniões pedagógicas e professores de Educação Física: espaço de formação docente? In: CONGRESSO DE CIÊNCIAS DO DESPORTO E EDUCAÇÃO FÍSICA DOS PAÍSES DE LÍNGUA PORTUGUESA, 12, 2008, Porto Alegre. Anais... Porto Alegre: ESEF/UFRGS, 2008.

DARIDO, S.C.; NETO, L.S. O contexto da Educação Física na escola. In: DARIDO, S.C.; RANGEL, I.C.A. (Coords.). Educação Física na escola: implicações para a prática pedagógica. Rio de Janeiro: Guanabara Koogan, 2005.

GARCÍA, C.M. Formação de professores - para uma mudança educativa. Porto: Porto Editora, 1999.

GHEDIN, E.; ALMEIDA, M.I.; LEITE, Y.U.F. Formação de professores: caminhos e descaminhos da prática. Brasília: Líber Livro Editora, 2008. 
GÜNTHER, M.C.C.; MOLINA NETO, V. Formação permanente de professores de Educação Física na rede municipal de ensino de Porto Alegre no período de 1989 a 1999 um estudo a partir de quatro escolas da rede, 2000. 204 f. Dissertação (Mestrado em Ciências do Movimento Humano) - Universidade Federal do Rio Grande do Sul, Porto Alegre, 2000.

ILHA, F.R. da S.; MARQUES, M.N.; KRUG, H.N. Os condicionantes sociais que atuam sobre o ecossistema escolar: um estudo de caso com professores de Educação Física. Boletim Brasileiro de Educação Física, Brasília, v.10, n.1, p.1-15, jan./fev., 2010. Disponível em: http://www.boletimef.org/biblioteca/2706/Condicionantes-sociais-que-atuam-sobre-o-e... . Acessado em: 21 jan. 2010.

KRUG, H.N. Formação de professores reflexivos: ensaios e experiências. Santa Maria: O Autor, 2001.

KRUG, H.N. Rede de autoformação participada como forma de desenvolvimento do profissional de Educação Física, 2004. 220 f. Tese (Doutorado em Ciência do Movimento Humano) - Universidade Federal de Santa Maria, Santa Maria, 2004 a.

KRUG, H.N. Professores de Educação Física Escolar: do isolamento profissional à reflexão colaborativa. Revista Biomotriz, Cruz Alta: UNICRUZ, 2006 (PP. 80-94).

MARQUES, M.N et al. Um olhar voltado para o percurso profissional dos professores de Educação Física: reflexões e perspectivas. In: SEMINÁRIO NACIONAL DE FORMAÇÃO DE PROFESSORES, 3, 2009. Santa Maria. Anais... Santa Maria: UFSM, 2009. p.7.

MARQUES, M.N.; KRUG, H.N. Os problemas sentidos no decurso da carreira de professores de Educação Física Escolar e a relação com os momentos de ruptura profissional. In: SIMPÓSIO NACIONAL DE EDUCAÇÃO FÍSICA, XXIX, 2009. Pelotas. Anais... Pelotas: ESEF-UFPEL, 2009 (pp.1-12).

MARTINS, G.A. Estudo de caso: uma estratégia de pesquisa. São Paulo: Atlas, 2006.

MOLINA, R.M. O enfoque teórico metodológico qualitativo e o estudo de caso: uma reflexão introdutória. In: MOLINA NETO, V.; TRIVINÕS, A.S. (Org.). A pesquisa qualitativa na Educação Física: alternativas metodológicas. Porto Alegre: Editora da UFRGS/Sulina, 2004 (pp. 95-105).

MOLINA NETO, V.; MOLINA, R.K. Identidade e perspectivas na Educação Física na América do Sul: formação profissional em Educação Física no Brasil. In: BRACHT, V.; CRISORIO, R. (Orgs.). A Educação Física no Brasil e na Argentina: identidade, desafios e perspectivas. Campinas: Autores Associados; Rio de Janeiro: PROSUL, 2003. p.259-278.

MOLINA NETO, V.; BOSSLE, F. O ofício de ensinar e pesquisar na Educação Física Escolar. In: MOLINA NETO, V.; MOLINA, R.K. (Org.). Pesquisa qualitativa em Educação Física Escolar: a experiência do F3P-EFICE. Porto Alegre: Sulina, 2010. p.09-36.

NEIRA, M.G. Educação Física: desenvolvendo competências. São Paulo: Phorte, 2006.

NÓVOA, A. Formação de professores e a profissão docente. In: NÓVOA, A. (Coord.). Os professores e a sua formação. Lisboa: Publicações Dom Quixote, 1992 (pp.15-34). 
NÓVOA, A. (Org.). Profissão professor. 2. ed. Porto: Porto Editora, 1995.

PÉREZ GÓMEZ, A.I. A função e formação do professor/a no ensino para a compreensão: diferentes perspectivas. In: SACRISTÁN, J.G.; PÉREZ GÓMEZ, A.I. (Orgs.). Compreender e transformar o ensino. 4. ed. Porto Alegre: Artmed, 2000 (pp.353 - 379).

PÉREZ GÓMEZ, A.I. A cultura escolar na sociedade neoliberal. Porto Alegre: ArtMed, 2001.

SANTIN, S. Educação Física e processo educacional. In: Educação Física - educar e profissionalizar. Porto Alegre: Edições EST, 1999 (pp.21- 51).

TRIVIÑOS, A.N.S. Introdução à pesquisa em ciências sociais: pesquisa qualitativa em educação. São Paulo: Atlas, 1987.

VASCONCELLOS, C.S. Para onde vai o professor? Resgate do professor como sujeito de transformação. 12. ed. São Paulo: Libertad, 2007. 